\title{
Epidemiological and nutritional transition in Mexico: rapid increase of non-communicable chronic diseases and obesity
}

\author{
Juan A Rivera', Simón Barquera ${ }^{1, *}$, Fabricio Campirano ${ }^{1}$, Ismael Campos ${ }^{1}$, \\ Margarita Safdie ${ }^{1}$ and Víctor Tovar ${ }^{2}$ \\ ${ }^{1}$ Centro de Investigación en Nutrición y Salud, Instituto Nacional de Salud Pública, Avenida Universidad 655 Col. \\ Santa María Ahuacatitlán, Cuernavaca, Morelos, Mexico, CP 62508: ${ }^{2}$ Centro de Investigación en Poblaciones, \\ Instituto Nacional de Salud Pública, Cuernavaca, Morelos, Mexico
}

\begin{abstract}
Objective: The objective of this paper is to characterise the epidemiological and nutritional transition and their determinants in Mexico.

Design: Age-adjusted standardised mortality rates (SMRs) due to acute myocardial infarction (AMI), diabetes mellitus and hypertension were calculated for 1980-1998. Changes in the prevalences of overweight and obesity in women and children and of dietary intake from 1988 to 1999 were also used in the analysis. Quantities of food groups purchased by adult equivalent (AE) and food expenditures away from home between 1984 and 1989 were used to assess trends. All information was analysed at the national and regional levels, and by urban and rural areas.

Results: SMR for diabetes, AMI and hypertension increased dramatically parallel to obesity at the national and regional levels. Fat intake in women and the purchase of refined carbohydrates, including soda, also increased.

Discussion: The results suggest that obesity is playing a role in the increased SMRs of diabetes, AMI and hypertension in Mexico. Total energy dietary intake and food purchase data could not explain the rise in the prevalence of obesity. The increases in fat intake and the purchase of refined carbohydrates may be risk factors for increased mortality. Information on physical activity was not available.

Conclusion: SMRs due to diabetes, hypertension and AMI have increased dramatically in parallel with the prevalence of obesity; therefore actions should be taken for the prevention of obesity. Reliable information about food consumption and physical activity is required to assess their specific roles in the aetiology of obesity.
\end{abstract}

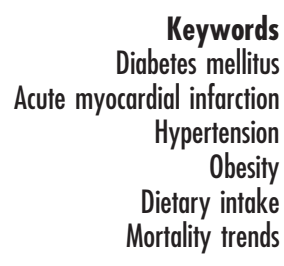

Mexico is currently undergoing an epidemiological transition $^{1-4}$ characterised as the retarded variant of the transition model ${ }^{4,5}$. Several studies have described a phenomenon of polarisation in the country, where the more developed industrial states (those in the north) have epidemiological profiles similar to those of developed countries and less developed states reflect pre-transitional epidemiological profiles ${ }^{2,3,6}$. This polarisation has been attributed to the uneven distribution of wealth, education, access to health services and overall quality of basic services between rich and poor families ${ }^{1-3}$; however, in recent years obesity, diabetes and other non-communicable chronic diseases (NCCDs) have been increasing among the $\operatorname{poor}^{7,8}$. Moreover, a growing number of studies are finding an association of low birth weight with obesity, diabetes and coronary heart disease in adults ${ }^{9-13}$. Access to inexpensive but high energy-dense foods is rising and physical activity is decreasing, since large numbers of people now live in urban areas and are engaged in less physical activity ${ }^{14,15}$. The objective of this paper is to characterise the epidemiological and nutritional transitions and their determinants in Mexico.

\section{Methods}

There were two types of information for this study: (1) datasets from national probabilistic surveys that were analysed specifically for this paper and (2) information that had been published. The sources of information are described below.

\section{Trends of NCCD mortality in Mexico}

Mortality rates for acute myocardial infarction (AMI), diabetes mellitus and hypertension were obtained from the National Institute of Informatics, Statistics and Geography (INEGI) using the International Classification of Diseases, version 9 (ICD-9) for the years 1980 to $1997^{16}$ and version 10 (ICD-10) for $1998^{17}$. AMI included causes 410 to 414 (ICD-9) in 1980-1997 and I20 to I25 (ICD-10) in 1998. Diabetes mellitus included cause 250 (ICD-9) in 1980-1997 and E10 to E14 (ICD-10) in 1998. Hypertension included causes 401 to 405 (ICD-9) in 1980-1987 and I10 to I15 (ICD-10) in 1998. The mortality rates were calculated using population estimates for Mexico provided by INEGI. Once crude mortality rates were obtained, they 
were age-adjusted according to the new World Health Organization (WHO) reference population to allow international comparisons ${ }^{18}$. In addition, the relative change from 1980 to 1998 was estimated for each year and compared across the selected mortality causes.

\section{Geographic location}

Age-adjusted standardised mortality rate (SMR) data are also presented by four regions to allow comparisons with the Mexican Nutrition Survey and the National Chronic Diseases Survey, which were representative of four regions constructed on the basis of common characteristics, such as development and per capita income ${ }^{19}$. The states included in each region are: North (Baja California, Baja California Sur, Coahuila, Chihuahua, Durango, Nuevo León, Sonora, Sinaloa, Tamaulipas and Zacatecas), Central (Aguascalientes, Colima, Guanajuato, Hidalgo, Jalisco, México, Michoacán, Nayarit, Queretaro, San Luis Potosí and Tlaxcala), Mexico City and South (Campeche, Chiapas, Guerrero, Morelos, Oaxaca, Puebla, Quintana Roo, Tabasco, Veracruz and Yucatán). Data were also analysed by rural (population equal to or less than 15000) or urban location (population more than 15000). All data were weighted for the analysis using the corresponding expansion factors provided by INEGI.

\section{Diabetes, bypertension and hyperlipidaemia}

Prevalences of diabetes, hypertension and hypercholesterolaemia were obtained from the National Chronic Diseases Survey (NCDS) conducted in 1992-93 in a probabilistic sample of adults 20-69 years old from urban locations (more than 2500 habitants) ${ }^{20}$. The survey was designed to be representative of urban areas at the national level and for the four regions identified above. Hypertension was defined as systolic pressure $\geq 140 \mathrm{mmHg}$ and/or diastolic pressure $\geq 90 \mathrm{mmHg}$ during two measurements. Diabetes was defined as a concentration of glucose in fasting venous blood serum $\geq 120 \mathrm{mg} \mathrm{dl}^{-1}$ or $\geq 200 \mathrm{mg} \mathrm{dl}^{-1}$ in casual samples. Hypercholesterolaemia was defined as the concentration of total cholesterol in plasma $\geq 240 \mathrm{mg} \mathrm{dl}^{-1}$.

\section{Obesity and dietary intake}

Published information about malnutrition and obesity are based on two probabilistic National Nutrition Surveys (NNS) conducted in 1988 (NNS-88) and 1999 (NNS-99). Both surveys were designed to be representative at the national level and by the four regions described above. These surveys collected information of children under 5 years old and reproductive-age women (12-49 years old). For this paper, published information about overweight in children $0-5$ years of age, as well as body mass index (BMI) in women 18-49 years old, is reported. Overweight and obesity in women were defined according to the WHO criteria for body mass index: BMI of 25.0$29.9 \mathrm{~kg} \mathrm{~m}^{-2}$ for overweight and $\geq 30 \mathrm{~kg} \mathrm{~m}^{-2}$ for obesity ${ }^{21}$.
Overweight in children was defined ${ }^{22}$ as a $Z$-score of weight-for-height above +2 . Dietary intake from the two NNS is presented for women 12-49 years of age. Both surveys used the 24-hour recall method. The median total energy intake (kcal) as well as the intake of protein, carbohydrates and fat $(\mathrm{g})$ is presented.

\section{Quantity of food purchased per adult equivalent}

Household food quantities purchased, per adult equivalent, were used as a proxy for food intake. Data from six National Income and Expenditure Surveys (NIES) conducted between 1984 and 1998 were used. These surveys were collected by the National Institute of Geography, Informatics and Statistics. They contain nationally representative information of about 15000 households and their members. Information from the following years was available: 1984, 1988, 1992, 1994, 1996 and 1998.

\section{Housebold adult equivalents ( $A E$ )}

For each household member, the individual adult equivalent was obtained by dividing the Recommended Dietary Allowance (RDA) for energy ${ }^{23}$ of each household member, according to the specific age and sex, by the average energy RDA for an adult $(2550 \mathrm{kcal})$. The sum of all of the individual adult equivalents within a household was further computed to obtain the household adult equivalent (AE). Family members not currently living in the house were excluded from this estimation, but their contribution to the household income was included in the total household income.

\section{Food expenditure}

About 215 foods were included in each NIES, with slight variations in some years. Expenditures are reported per week in Mexican pesos. A database with household expenditures for each food per household was developed. Expenditures for selected food groups were created and converted to US dollars (US\$) using the average exchange rate of the year in which the survey was conducted. The food groups were: (1) fruits, vegetables and legumes; (2) meat, poultry and eggs; (3) milk and dairy products; (4) cereals; (5) fats and oils; (5) sugars and refined carbohydrates (which, in addition to carbohydrates, included all sugar-sweetened beverages). Results are presented for the food groups and for two individual food items, already included in the food groups, that have high consumption in the Mexican diet: tortilla (the traditional staple) and soda. The median weekly total food expenditure per AE was obtained, as well as the median food group expenditure per AE.

\section{Quantity of food purchased per adult equivalent}

Food prices experienced important changes during the study period, even after adjusting for inflation. This was probably due, in part, to removal of food subsidies during this period for staples (tortilla and white bread) and milk, 
which the government had been implementing for decades. Therefore, in order to have a better proxy for food intake, expenditures were further converted into food quantities. For every survey, food expenditures for each food group were divided by the corresponding food prices for the corresponding year. Prices employed were weighted averages of the food items within each food group that contribute to most of the food intake in that group, according to food intake data from the NNS-99. The contribution to total intake (expressed in $\mathrm{g}$ ) of the foods selected for each group ranged between 70\% and 99\%. Averages were weighted, by the relative contribution of each food to the sum of the foods selected, to obtain the average price. Units of measure are kilogram $(\mathrm{kg})$ for most food items, although litre (1) is used for some foods.

\section{Quantity index}

The quantities of purchased food and food groups were further indexed using the 1984 quantities as the reference.

\section{Food expenditure away from bome}

Food expenditures away from home were available for five of the six NIES: 1988, 1992, 1994, 1996 and 1998. The proportion of households with food expenditures away from home, and the amount spent per adult equivalent adjusted for inflation (expressed in 1993 Mexican pesos), was calculated for the five years for which information is available. In addition, the average food expenditure away from home for the entire population was obtained.

\section{Geographic location}

The data were divided into the four regions described above to allow comparisons with the National Nutrition and National Chronic Diseases Surveys. All data were weighted for the analysis using the corresponding expansion factors provided by INEGI.

Data analyses were performed using the statistical software package, SPSS version $10^{24}$.

\section{Results}

\section{Mortality}

SMRs for AMI, diabetes mellitus and hypertension from 1980 to 1998, for the national level and by region, are presented in Table 1. An index SMR relative to 1980 is also presented in parentheses in Table 1 and in Fig. 1. The latter presents SMR for cirrhosis and vascular cerebral disease as references for comparison with the three causes of interest.

Dramatic increases in SMR between 1980 and 1998 were observed for the three causes of death analysed. The increases over the period 1980-1998 were 53\% for AMI, $62 \%$ for diabetes and 55\% for hypertension. A sharp increase for AMI is observed in the last 10 years (19881998). A steady increase for diabetes is observed over most of the period (1980-1997), with a sharp increase in 1998. And an abrupt increase for hypertension is observed between 1983 and 1985, with a slower slope thereafter.

The baseline SMR (1980) was higher for Mexico City and the North, relative to the less developed regions (Centre and South), for the three causes of death; however, the relative increments are substantially larger for the South and Centre compared with the more developed regions (North and Mexico City). The relative increments in the South and Centre range from $70 \%$ to $140 \%$ for the different causes; the corresponding figures for the North and Mexico City range between $-10 \%$ and $50 \%$.

\section{Prevalence of chronic disease morbidity}

The national prevalences of diabetes, hypertension and hypercholesterolaemia in 20- to 69-year-old urban adults from the $\operatorname{NCDS}^{20}$ was $28.5 \%$ for males and $25.1 \%$ for females, with higher prevalences in the North $(30.3 \%$ males, $26.1 \%$ females), followed by the South (31.3\% males, $24.6 \%$ females), the Centre (27.2\% males, $26.7 \%$ females) and Mexico City (25.0\% males, 23.0\% females). The prevalence of diabetes at the national level was $7.2 \%$ for both sexes, with higher prevalences for the North $(8.6 \%$ males, 9.3\% females), followed by the South (7.3\% males, $6.1 \%$ females $)$, the Centre (6.0\% males, $7.5 \%$ females) and Mexico City (6.9\% males, 6.1\% females). The prevalence of hypercholesterolaemia at the national level was $10 \%$ for males and $8.1 \%$ for females, with higher prevalences in the Centre (12.0\% males, $9.7 \%$ females), followed by Mexico City (11.9\% males, 9.3\% females), the South $(7.7 \%$ males, $7.2 \%$ females) and the North (8.3\% males, $6.3 \%$ females).

\section{Overweight and obesity}

Results for prevalences of overweight and obesity in women and overweight in children less than 5 years of age from published information of the NNS, conducted in 1988 and $1999^{25-27}$, are presented in Table 2.

The combined prevalences of overweight and obesity in women 18-49 years of age were 33.4\% in 1988 and 59.6\% in 1999, an increase of 26.2 percentage points, or $78 \%$ relative to the baseline prevalence. The highest prevalence in 1988 was in the North; the 11-year increments, relative to baseline prevalences, were about $70 \%$ in Mexico City and the North and more than $80 \%$ in the less developed regions ( $81.3 \%$ for the South and $101.4 \%$ for the Centre). A comparison of changes in overweight and obesity reveals that, in the 11-year period between the surveys, overweight at the national level increased almost $47 \%$, ranging from $29 \%$ in the North to $73 \%$ in the Centre, while obesity increased by $160 \%$, ranging from $133 \%$ in Mexico City to $174 \%$ in the Centre.

The prevalence of obesity in children under 5 years of age increased from $4.2 \%$ in 1988 to $5.3 \%$ in 1999 , a $26 \%$ increase. The highest prevalences in 1988 were in the North and Centre; however, the relative changes were 
much higher in Mexico City and the South (increases of over 80\%) than in the North (12.5\%) and the Centre $(-18.5 \%)$.

\section{Dietary intake}

Total energy intake at the national level was about $80 \%$ of the recommended intake ${ }^{23}$, reflecting the underreporting often shown in 24-hour recall data. Fat intake in 1999 represented over $30 \%$ of the energy intake in all regions, except the South, while carbohydrate intake was between 55 and 60\%. Total energy and carbohydrates intake showed a declining trend in all regions but the South, from 1988 to 1999 . However, the declines were small, relative to the standard deviation of the distribution (less than 0.2 of a standard deviation). Protein intake declined from 1988 to 1999 in all regions. The difference in protein intake is relatively large for all regions $(\approx 0.33-0.45$ of a standard deviation) except for the South $(\approx 0.20$ of a standard deviation). Fat intake shows a change from 1988 to 1999 similar to the national level and consistent in all regions; the increases are relatively large in the Centre, South and Mexico City ( $\approx 0.25-0.45$ of a standard deviation) and smaller for the North $(\approx 0.25 \text { of a standard deviation })^{27,28}$.

\section{Quantities of food purchased per adult equivalent}

Mean quantities of food purchased in the households per adult equivalent for the six years for which data were available (1984 to 1998) are presented in Table 3. Information is presented for the food groups and food items listed in the Methods section.

A general decline in food quantities purchased at the national level is observed for food groups from 1984 to 1998, except for sugars and refined carbohydrates, which increased by $10 \%$. In general, food quantities purchased remained constant or increased from 1984 to 1989 , declined in 1992, increased again in 1994, and declined sharply thereafter. The exceptions are cereals, which declined steadily during the study period, and sugars, which increased after 1992. Trends in individual food items agree, in general, with the findings for the corresponding food groups. Tortillas follow the steady decline observed in cereals, while soda shows an important increase in quantity purchased without decreases in any particular year. Results in urban and rural areas show trends almost identical to those observed at the national level, although the quantities of food groups purchased are higher in urban areas for the whole period. This difference is substantial (almost double) for most food items, except for fats and oils and for sugars. Tortilla, the traditional staple in Mexico, is the only food item with larger quantities purchased in rural than in urban areas.

Purchased food quantities show similar trends in the four regions except for sugars, which declined slightly in the South and increased slightly in the other three regions, and fats and milk, which declined in all areas except Mexico City. Tortillas showed no change, or a small decline, in Mexico City, with larger declines in the other three areas, while soda showed an important increase in Mexico City (150\%), with more modest increases in the other regions (20-30\%).

The purchased quantities of fruits, vegetables and legumes and meat, poultry and eggs were substantially higher (1.5 to 2.5 times) in Mexico City compared with the other three regions during the period. Purchased quantities for sugars and refined carbohydrates were larger in Mexico City and the North (25-40\% higher) compared with the other regions during the period.

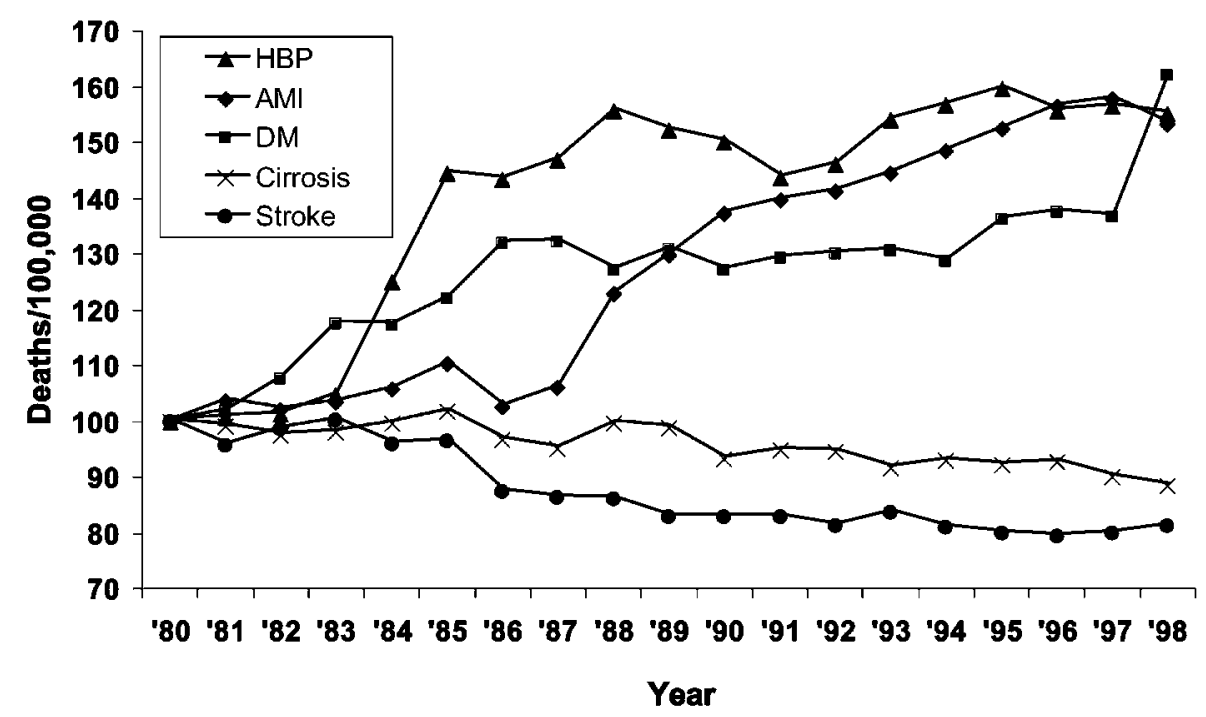

Fig. 1 Age-adjusted death rates, relative to 1980, from high blood pressure (HBP), diabetes mellitus (DM), acute myocardial infarction (AMI), cirrhosis and stroke from 1980 to 1998 in Mexico. HBP included causes 401 to 405 (ICD-9) and I10 to I15 (ICD-10). DM included cause 250 (ICD-9) and E10 to E14 (ICD-10). AMI included causes 410 to 414 (ICD-9) and I20 to I25 (ICD-10). Cirrhosis included causes $571.2,571.5,571.6$ (ICD-9) and K70.3, K74.3, K74.6 (ICD-10). Stroke included causes 430 to 438 (ICD-9) and I60 to I69 (ICD-10) 
Table 1 Mortality due to diet-related chronic diseases in Mexico from 1980 to 1998

\begin{tabular}{|c|c|c|c|c|c|c|c|c|c|}
\hline \multirow[b]{2}{*}{ Cause } & \multirow[b]{2}{*}{ Year } & \multirow{2}{*}{$\begin{array}{l}\text { Number } \\
\text { of cases }\end{array}$} & \multirow{2}{*}{$\begin{array}{l}\text { Crude mortality } \\
\text { rate }^{*}\end{array}$} & \multirow{2}{*}{$\begin{array}{l}\text { Standardised } \\
\text { mortality } \\
\text { rate }(\text { SMR }) \dagger\end{array}$} & \multicolumn{4}{|c|}{ Regional SMR $\ddagger$} & \multirow{2}{*}{$\begin{array}{c}\text { SMR increase } \\
\text { relative } \\
\text { to } 1980(\%)\end{array}$} \\
\hline & & & & & North & Central & Mexico City & South & \\
\hline \multirow[t]{19}{*}{ Acute myocardial infarction§ } & 1980 & 13058 & 17.5 & 39.5 & 59.2 & 34.1 & 45.2 & 27.5 & 100.0 \\
\hline & 1981 & 13406 & 18.3 & 40.9 & 65.4 & 35.6 & 42.1 & 27.9 & 103.6 \\
\hline & 1982 & 13537 & 18.0 & 40.2 & 64.2 & 34.8 & 42.4 & 27.1 & 101.9 \\
\hline & 1983 & 14133 & 18.4 & 40.7 & 65.2 & 35.0 & 42.3 & 27.8 & 103.2 \\
\hline & 1984 & 14874 & 19.0 & 41.7 & 64.4 & 36.7 & 42.8 & 29.1 & 105.7 \\
\hline & 1985 & 16030 & 20.0 & 43.5 & 64.0 & 38.1 & 43.2 & 33.9 & 110.3 \\
\hline & 1986 & 15292 & 18.8 & 40.5 & 58.1 & 38.3 & 39.5 & 29.4 & 102.6 \\
\hline & 1987 & 16517 & 19.6 & 41.8 & 68.4 & 38.7 & 38.4 & 29.0 & 106.0 \\
\hline & 1988 & 19408 & 22.9 & 48.5 & 72.4 & 45.9 & 44.9 & 34.2 & 122.9 \\
\hline & 1989 & 21347 & 24.5 & 51.2 & 78.6 & 46.0 & 50.2 & 35.7 & 129.8 \\
\hline & 1990 & 23398 & 26.5 & 54.2 & 79.0 & 48.3 & 56.7 & 39.6 & 137.3 \\
\hline & 1991 & 21520 & 27.3 & 55.1 & 79.7 & 49.9 & 58.6 & 39.2 & 139.7 \\
\hline & 1992 & 25646 & 28.1 & 55.7 & 77.2 & 52.3 & 59.9 & 39.8 & 141.2 \\
\hline & 1993 & 27302 & 29.4 & 57.0 & 76.8 & 53.4 & 60.5 & 43.1 & 144.5 \\
\hline & 1994 & 29092 & 30.8 & 58.6 & 79.8 & 54.1 & 62.2 & 44.4 & 148.4 \\
\hline & 1995 & 30945 & 32.3 & 60.2 & 82.0 & 54.9 & 60.8 & 47.8 & 152.5 \\
\hline & 1996 & 32746 & 33.8 & 61.7 & 83.1 & 56.3 & 60.3 & 51.3 & 156.3 \\
\hline & 1997 & 34651 & 25.0 & 62.2 & 85.0 & 57.4 & 61.0 & 50.1 & 157.8 \\
\hline & 1998 & 34587 & 34.8 & 60.4 & 85.6 & 61.5 & 63.8 & 55.2 & 153.2 \\
\hline \multirow[t]{19}{*}{ Diabetes mellitus $q$} & 1980 & 14515 & 20.8 & 46.9 & 52.5 & 42.3 & 76.6 & 33.9 & 100.0 \\
\hline & 1981 & 15299 & 21.3 & 47.8 & 52.9 & 41.8 & 81.2 & 35.2 & 101.8 \\
\hline & 1982 & 16616 & 22.6 & 50.5 & 58.5 & 48.1 & 76.2 & 35.1 & 107.7 \\
\hline & 1983 & 18726 & 25.0 & 55.2 & 64.6 & 53.0 & 76.1 & 40.2 & 117.6 \\
\hline & 1984 & 19274 & 25.2 & 55.0 & 64.5 & 53.8 & 71.6 & 40.6 & 117.2 \\
\hline & 1985 & 20763 & 26.5 & 57.2 & 63.8 & 56.3 & 78.5 & 42.6 & 122.0 \\
\hline & 1986 & 23100 & 28.9 & 61.8 & 72.3 & 60.9 & 74.1 & 48.6 & 131.8 \\
\hline & 1987 & 23882 & 29.3 & 62.1 & 70.5 & 58.6 & 77.9 & 51.6 & 132.2 \\
\hline & 1988 & 24986 & 28.7 & 59.6 & 62.0 & 59.8 & 73.4 & 50.4 & 127.0 \\
\hline & 1989 & 25519 & 30.2 & 61.4 & 72.9 & 59.2 & 71.8 & 49.2 & 130.8 \\
\hline & 1990 & 25592 & 29.7 & 59.6 & 67.7 & 60.4 & 72.3 & 45.4 & 127.1 \\
\hline & 1991 & 26989 & 30.8 & 60.6 & 65.8 & 63.8 & 69.2 & 47.7 & 129.2 \\
\hline & 1992 & 28135 & 31.6 & 61.0 & 64.0 & 65.5 & 69.2 & 48.2 & 129.9 \\
\hline & 1993 & 29428 & 32.5 & 61.2 & 63.6 & 66.3 & 66.4 & 50.1 & 130.5 \\
\hline & 1994 & 30156 & 32.8 & 60.4 & 62.4 & 64.4 & 64.1 & 51.7 & 128.7 \\
\hline & 1995 & 33168 & 35.5 & 63.9 & 64.4 & 70.3 & 66.5 & 53.6 & 136.2 \\
\hline & 1996 & 34692 & 36.6 & 64.5 & 64.8 & 71.2 & 64.7 & 55.8 & 137.5 \\
\hline & 1997 & 35835 & 37.3 & 64.2 & 66.2 & 71.1 & 61.9 & 55.0 & 136.7 \\
\hline & 1998 & 41714 & 45.3 & 76.1 & 83.7 & 90.6 & 79.0 & 72.2 & 162.1 \\
\hline \multirow[t]{19}{*}{ High blood pressure\| } & 1980 & 3221 & 4.7 & 10.9 & 15.9 & 8.9 & 15.8 & 7.2 & 100.0 \\
\hline & 1981 & 3394 & 4.7 & 10.9 & 13.7 & 9.2 & 17.7 & 7.9 & 100.6 \\
\hline & 1982 & 3525 & 4.8 & 11.0 & 13.4 & 10.1 & 17.0 & 7.4 & 101.3 \\
\hline & 1983 & 3727 & 4.9 & 11.4 & 13.6 & 10.4 & 16.5 & 8.4 & 104.6 \\
\hline & 1984 & 4580 & 6.0 & 13.6 & 16.4 & 12.8 & 18.7 & 9.8 & 124.9 \\
\hline & 1985 & 5468 & 7.0 & 15.7 & 18.5 & 15.0 & 19.6 & 12.3 & 144.4 \\
\hline & 1986 & 5602 & 7.0 & 15.6 & 17.3 & 15.5 & 20.3 & 11.9 & 143.3 \\
\hline & 1987 & 5907 & 7.2 & 16.0 & 18.5 & 15.5 & 21.1 & 11.9 & 146.8 \\
\hline & 1988 & 6416 & 7.7 & 16.9 & 18.6 & 17.3 & 20.8 & 13.0 & 155.5 \\
\hline & 1989 & 6550 & 7.7 & 16.5 & 19.0 & 17.5 & 18.4 & 12.3 & 152.1 \\
\hline & 1990 & 6647 & 7.7 & 16.3 & 19.0 & 16.7 & 15.8 & 13.8 & 149.9 \\
\hline & 1991 & 6587 & 7.5 & 15.6 & 16.9 & 16.6 & 14.8 & 13.7 & 143.5 \\
\hline & 1992 & 6969 & 7.8 & 15.9 & 17.1 & 16.9 & 15.0 & 14.2 & 146.1 \\
\hline & 1993 & 7627 & 8.4 & 16.7 & 18.4 & 17.5 & 14.8 & 15.4 & 153.9 \\
\hline & 1994 & 8065 & 8.8 & 17.0 & 18.7 & 18.4 & 14.3 & 15.3 & 156.6 \\
\hline & 1995 & 8560 & 9.2 & 17.3 & 18.7 & 18.3 & 15.7 & 15.9 & 159.5 \\
\hline & 1996 & 8643 & 9.1 & 16.9 & 17.8 & 18.3 & 14.0 & 16.1 & 155.5 \\
\hline & 1997 & 9087 & 9.4 & 17.0 & 17.9 & 17.9 & 14.3 & 16.7 & 156.5 \\
\hline & 1998 & 9361 & 9.6 & 16.9 & 18.7 & 20.3 & 14.4 & 17.7 & 155.1 \\
\hline
\end{tabular}

\footnotetext{
* Per 100000 inhabitants.
}

†Age-standardised according to WHO criteria $^{17}$.

$\ddagger$ Regions include the following states: North - Baja California, Baja California Sur, Coahuila, Chihuahua, Durango, Nuevo León, Sonora, Sinaloa, Tamaulipas and Zacatecas; Central - Aguascalientes, Colima, Guanajuato, Hidalgo, Jalisco, México, Michoacán, Nayarit, Queretaro, San Luis Potosí and Tlaxcala; Mexico City; and South - Campeche, Chiapas, Guerrero, Morelos, Oaxaca, Puebla, Quintana Roo, Tabasco, Veracruz and Yucatán.

$\S$ Acute myocardial infarction included causes 410 to 414 (ICD-9) and I20 to I25 (ICD-10).

- Diabetes mellitus included cause 250 (ICD-9) and E10 to E14 (ICD-10).

|| High blood pressure included causes 401 to 405 (ICD-9) and I10 to I15 (ICD-10). 
Table 2 Overweight and obesity in women and children and dietary intake according to the National Nutrition Surveys in 1988 and 1999

\begin{tabular}{|c|c|c|c|c|c|c|c|c|c|c|}
\hline \multirow[b]{3}{*}{ Variables } & \multirow{2}{*}{\multicolumn{2}{|c|}{ National }} & \multicolumn{8}{|c|}{ Regions } \\
\hline & & & \multicolumn{2}{|c|}{ North } & \multicolumn{2}{|c|}{ Central } & \multicolumn{2}{|c|}{ Mexico City } & \multicolumn{2}{|c|}{ South } \\
\hline & 1988 & 1999 & 1988 & 1999 & 1988 & 1999 & 1988 & 1999 & 1988 & 1999 \\
\hline \multicolumn{11}{|c|}{ Prevalence of overweight and obesity (\%) ${ }^{a, b}$} \\
\hline \multicolumn{11}{|c|}{ Women $18-49$ years } \\
\hline Overweight & 24.0 & 35.2 & 26.3 & 34.0 & 21.0 & 36.4 & 25.6 & 37.7 & 22.3 & 34.5 \\
\hline Obesity & 9.4 & 24.4 & 11.8 & 31.3 & 8.1 & 22.2 & 9.2 & 21.4 & 8.2 & 20.8 \\
\hline Overweight and obesity & 33.4 & 59.6 & 38.1 & 65.3 & 29.1 & 58.6 & 34.8 & 59.1 & 30.5 & 55.3 \\
\hline Children $0-5$ years & 4.2 & 5.3 & 6.4 & 7.2 & 5.4 & 4.4 & 2.8 & 5.3 & 2.9 & 5.3 \\
\hline \multicolumn{11}{|l|}{$\begin{array}{l}\text { Dietary intake (women) } \\
\text { 24-hour recall }\end{array}$} \\
\hline \multicolumn{11}{|l|}{ Energy (kcal) } \\
\hline Mean & 1721 & 1636 & 1700 & 1495 & 1713 & 1659 & 1707 & 1568 & 1750 & 1742 \\
\hline SD & (810) & (769) & (761) & (719) & (748) & (727) & (832) & (772) & (847) & (817) \\
\hline Median & 1568 & 1531 & 1575 & 1422 & 1568 & 1557 & 1536 & 1413.5 & 1580 & 1636 \\
\hline \multicolumn{11}{|l|}{ Protein $(\mathrm{g})$} \\
\hline $\begin{array}{l}\text { Mean } \\
\text { SD }\end{array}$ & $\begin{array}{l}63 \\
(34)\end{array}$ & $\begin{array}{l}52 \\
(33)\end{array}$ & $\begin{array}{l}63 \\
(34)\end{array}$ & $\begin{array}{l}49 \\
(43)\end{array}$ & $\begin{array}{l}63 \\
(34)\end{array}$ & $\begin{array}{l}52 \\
(28)\end{array}$ & $\begin{array}{l}68 \\
(37)\end{array}$ & $\begin{array}{l}51 \\
(29)\end{array}$ & $\begin{array}{l}61 \\
(32)\end{array}$ & $\begin{array}{l}54 \\
(33)\end{array}$ \\
\hline Median & 56 & 47 & 56 & 45 & 56 & 47 & 60 & 45 & 55 & 48 \\
\hline Protein (\% of energy) & 14.6 & 12.7 & 14.8 & 13.1 & 14.7 & 12.5 & 15.9 & 13.0 & 13.9 & 12.4 \\
\hline \multicolumn{11}{|l|}{ Carbohydrates (g) } \\
\hline Mean & 257 & 235 & 247 & 203 & 259 & 237 & 242 & 215 & 269 & 265 \\
\hline SD & (139) & (117) & (130) & (103) & (136) & (108) & (132) & (104) & (151) & (133) \\
\hline Median & 227 & 219 & 224 & 184 & 230 & 225 & 213 & 201 & 237 & 245 \\
\hline Carbohydrates (\% of energy) & 59.7 & 57.5 & 58.1 & 54.3 & 60.5 & 57.1 & 56.7 & 54.8 & 61.4 & 60.8 \\
\hline \multicolumn{11}{|l|}{ Fat $(\mathrm{g})$} \\
\hline Mean & 45 & 55 & 48 & 55 & 44 & 56 & 47 & 57 & 43 & 52 \\
\hline SD & (25) & (37) & (25) & (35) & (26) & (38) & (25) & (38) & (25) & $\begin{array}{l}(37) \\
44\end{array}$ \\
\hline Median & 41 & 47 & 43 & 48 & 40 & 49 & 43 & 49 & 39 & \\
\hline Fat (\% of energy) & 23.5 & 30.3 & 25.4 & 33.1 & 23.1 & 30.4 & 24.8 & 32.7 & 22.1 & 26.9 \\
\hline \multicolumn{11}{|c|}{ Sample size (not expanded): } \\
\hline \multicolumn{11}{|c|}{ 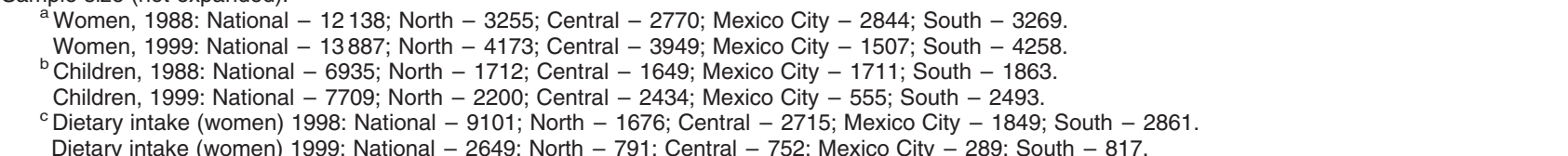 } \\
\hline
\end{tabular}

Purchased quantities for other food groups were not different among regions.

The purchased quantities of tortilla were smaller in Mexico City in 1984 but became similar to or slightly larger than quantities purchased in the other two regions by the end of the period.

Food expenditure away from home had a decreasing trend during the study period. The percentage of households with food expenditures away from home during the week prior to the interview was 22.5, 30.1, 28.2, 24.9 and 11.1 for 1988, 1992, 1994, 1996 and 1998, respectively. Food expenditures away from home per adult equivalent, expressed in 1993 Mexican pesos for households with such expenditures, were 225, 114, 160, 123 and 155, respectively. The average food expenditures away from home (in 1993 Mexican pesos) for the whole population were 50.6, 34.3, 45.2, 30.6 and 17.2, respectively.

\section{Discussion}

An increasing trend in SMRs from diabetes mellitus, AMI and hypertension was observed during the 19-year study period. The increases observed were considerable, ranging from 53\% to 62\%, relative to the SMR in 1980 . One possibility is that increases observed are explained by improvements in the quality of the deaths registry system in Mexico. In 1980, medical doctors certified $86 \%$ of total deaths, while in 1998 this figure increased to $96.8 \%{ }^{29}$. Illdefined causes decreased from $6.7 \%$ in 1980 to $2.0 \%$ in $1992^{29}$. Thus, it is possible that at least part of the sharp increases was due to improvements in the quality of the registry system. However, the relatively small magnitude of the increase in certifications by medical doctors and of the decrease in ill-defined causes of death relative to the increases in mortality for the three causes studied suggest that improvements in the registry system do not account for a significant part of the increases in mortality observed. This claim is further substantiated by the decline or lack of change in mortality rates for several other causes of death during the study period. For example, mortality rates due to accidents have decreased by about half during the period, deaths due to liver disease decreased by $28 \%$, and neonatal mortality remained constant ${ }^{30}$. As shown in Fig. 1, SMRs for cirrhosis and vascular cerebral disease decreased 
during the study period. Further support for the mortality findings is the morbidity information presented, which shows high prevalences of diabetes, hypertension and hypercholesterolaemia. Moreover, preliminary data of diabetes mortality in 1999 confirms the high SMR found in 1998, suggesting that the sharp increase observed from 1997 to 1998 seems to be real. Our conclusion is that important increases in SMR for the three causes studied actually took place.

Epidemiological studies indicate that the three causes of death are of multiple aetiologies and result from a variety of risk factors. Heredity plays a role in all, but the three causes of death share common risk factors such as obesity, inadequate dietary intakes (high energy, fat, cholesterol and carbohydrates intake) and physical inactivity.

Overweight and obesity increased dramatically during the last decade by $78 \%$. This increase is consistent with the increases in mortality for the three causes considered, for which obesity is a risk factor. Moreover, obesity rates parallel mortality rates in the four regions studied. The highest prevalences of overweight and obesity in 1984 were found in the North and in Mexico City, coincident with the highest SMRs during the first half of the 1980s in these regions. The changes in overweight and obesity in women from 1980 to 1999 were larger for the South and Centre, which is consistent with the largest increases in SMR in the same regions. Comparisons of trends in obesity and SMRs for the NCCDs suggest that overweight and obesity are playing an important role in the aetiology of these NCCDs in Mexico.

Energy intake in women did not increase between 1988 and 1999 as expected, given the increase in obesity. It is well known that 24-hour recall, the technique employed in both surveys, underestimates energy intake. The degree to which energy intake is underestimated is influenced by factors that changed between 1988 and 1999. For example, we have documented that obese women tend to underestimate their intake to a greater extent than non-obese women $^{31}$. The larger proportion of obese women in 1999 relative to 1988 suggests a higher degree of underreporting in 1999. We suspected that more women consumed food out of their homes in 1999 than in 1988. It is well known that underreporting is higher when food is consumed out of home. However, we found that food expenditure away from home did not increase during the study period. Despite the possible higher underestimation of intakes in 1999, fat intake increased substantially during the decade, both in absolute terms and relative to total energy intake. This is an important finding, given the role of fat intake as a risk factor for some NCCDs and obesity.

In addition to dietary intake data, we obtained quantities of food purchased by food groups using expenditure data from 1984 to 1998. The only quantities of food groups that were higher for Mexico City and the North in 1984 (at the time when SMRs for NCCDs and obesity were clearly higher in these two regions) were sugars and refined carbohydrates, which were 20-30\% above the quantities reported for the Centre and South. Mexico City also reported higher quantities of meat, poultry and eggs, which contain foods that are high in saturated fatty acids and cholesterol; however, Mexico City also reported the highest quantities of fruits, vegetables and legumes, which include foods that are considered protective for several NCCDs.

To explain the changes in SMRs for NCCDs and obesity during the study period, the changes in quantities of food purchased during the period were analysed. The only food group with increased quantities purchased was sugar and refined carbohydrates. Soda, a component of that group, showed a substantial increase. However, comparisons among regions show similar or larger changes in Mexico City and the North (the regions with the smallest change in SMR and obesity) relative to those observed in the Centre and South (the regions with the highest change in SMR and obesity). Therefore, the findings do not support attributing a role in explaining the changes in obesity observed to sugar and refined carbohydrates. One limitation of the food expenditure data used to construct quantities purchased is that, although questions are asked in the surveys to account for expenditures outside the home, no questions directed at identifying the particular foods purchased outside the home were made. Therefore, the expenditure data clearly underestimate all food consumed at work, at school or in the street. Results using food expenditure data indicate that food expenditures away from home not only did not increase from 1988 to 1998 , but actually dropped. These results suggest that energy and macronutrient intake out of the home did not increase during the study period. Unfortunately, we do not have information regarding the specific foods purchased away from home. Although unlikely, it could be possible that people spent less money but purchased larger amounts of cheaper foods. Therefore, we cannot be conclusive about the changes of energy and nutrient intake away from home using only food expenditure data.

We conclude that food expenditure data do not explain the increases in obesity observed during the period. However, the increasing trends in the quantities of sugars and refined carbohydrates purchased, and more particularly the purchase quantities of soda, could be associated with the increased mortality from NCCDs, and therefore should be considered a sign of caution. It is recommended that food policy and nutrition specialists should monitor the trends closely.

Taken together, energy dietary intake of women and quantities of food purchased per adult equivalent do not seem to explain the changes observed in obesity. However, higher fat dietary intakes may be partially responsible for the increases in obesity and NCCDs.

One limitation of the study is that we do not have reliable information about other lifestyle risk factors for NCCDs. For example, reduced physical activity may be an 


\begin{tabular}{|c|c|c|c|c|c|c|c|c|}
\hline \multirow[b]{2}{*}{ Food group } & \multirow[b]{2}{*}{ Year } & \multicolumn{7}{|c|}{ Region } \\
\hline & & North & Central & Mexico City & South & $\begin{array}{c}\text { More than } 15000 \\
\text { inhabitants }\end{array}$ & $\begin{array}{l}\text { Less than } 15000 \\
\text { inhabitants }\end{array}$ & Total \\
\hline \multirow[t]{6}{*}{ Fruits, vegetables and legumes } & 1984 & $6.1(1.0)$ & $7.0(1.0)$ & $11.8(1.0)$ & $6.2(1.0)$ & $9.5(1.0)$ & $4.9(1.0)$ & $7.5(1.0)$ \\
\hline & 1989 & $6.1(1.0)$ & $7.1(1.0)$ & $11.9(1.0)$ & $6.1(1.0)$ & $9.2(1.0)$ & $4.7(1.0)$ & $7.2(1.0)$ \\
\hline & 1992 & $4.4(0.7)$ & $5.7(0.8)$ & $12.1(1.0)$ & $4.2(0.7)$ & $7.0(0.7)$ & $3.6(0.7)$ & $5.5(0.7)$ \\
\hline & 1994 & $6.0(1.0)$ & $8.5(1.2)$ & 15.9 (1.3) & $5.9(1.0)$ & $9.9(1.0)$ & $5.3(1.1)$ & $7.9(1.1)$ \\
\hline & 1996 & $5.6(0.9)$ & $5.0(0.7)$ & $11.9(1.0)$ & $3.8(0.6)$ & $7.2(0.8)$ & $3.7(0.8)$ & $5.6(0.7)$ \\
\hline & 1998 & $4.4(0.7)$ & $5.0(0.7)$ & $10.4(0.9)$ & $3.9(0.6)$ & $6.6(0.7)$ & $3.6(0.7)$ & $5.3(0.7)$ \\
\hline \multirow[t]{6}{*}{ Meat, poultry and eggs } & 1984 & $3.9(1.0)$ & $4.9(1.0)$ & $7.5(1.0)$ & $3.8(1.0)$ & $6.1(1.0)$ & $2.5(1.0)$ & $4.8(1.0)$ \\
\hline & 1989 & 4.5 (1.2) & $4.5(0.9)$ & $6.9(0.9)$ & $4.1(1.1)$ & $5.8(1.0)$ & $2.6(1.0)$ & $4.7(1.0)$ \\
\hline & 1992 & $2.9(0.7)$ & $3.6(0.7)$ & $6.4(0.9)$ & $2.8(0.7)$ & $4.3(0.7)$ & $2.0(0.8)$ & $3.4(0.7)$ \\
\hline & 1994 & $4.3(1.1)$ & $5.2(1.1)$ & 9.6 (1.3) & $3.8(1.0)$ & $6.7(1.1)$ & $2.8(1.1)$ & $4.9(1.0)$ \\
\hline & 1996 & $4.3(1.1)$ & $3.3(0.7)$ & 7.9 (1.1) & $3.1(0.8)$ & $5.4(0.9)$ & $2.6(1.0)$ & $4.1(0.9)$ \\
\hline & 1998 & $3.6(0.9)$ & $3.1(0.6)$ & $7.1(0.9)$ & $3.4(0.9)$ & $4.8(0.8)$ & $2.5(1.0)$ & $3.9(0.8)$ \\
\hline \multirow[t]{6}{*}{ Milk and dairy products } & 1984 & $12.9(1.0)$ & $14.6(1.0)$ & $12.8(1.0)$ & $11.3(1.0)$ & $14.9(1.0)$ & $8.7(1.0)$ & 13.1 (1.0) \\
\hline & 1989 & $12.7(1.0)$ & $14.2(1.0)$ & $11.1(0.9)$ & $11.1(1.0)$ & $13.6(0.9)$ & $10.6(1.2)$ & $12.8(1.0)$ \\
\hline & 1992 & $9.3(0.7)$ & $10.0(0.7)$ & $11.9(0.9)$ & $6.5(0.6)$ & $10.0(0.7)$ & $7.2(0.8)$ & $9.3(0.7)$ \\
\hline & 1994 & $12.5(1.0)$ & $14.7(1.0)$ & $17.8(1.4)$ & $9.6(0.8)$ & $15.4(1.0)$ & $9.0(1.0)$ & $13.4(1.0)$ \\
\hline & 1996 & $12.7(1.0)$ & $10.6(0.7)$ & $13.8(1.1)$ & $6.8(0.6)$ & $12.7(0.9)$ & $6.5(0.7)$ & $10.9(0.8)$ \\
\hline & 1998 & $10.1(0.8)$ & $9.6(0.7)$ & $12.5(1.0)$ & $6.7(0.6)$ & $10.9(0.7)$ & $6.9(0.8)$ & $9.6(0.7)$ \\
\hline \multirow[t]{6}{*}{ Cereals $†$} & 1984 & $27.8(1.0)$ & $27.4(1.0)$ & $28.3(1.0)$ & $26.8(1.0)$ & $29.5(1.0)$ & $22.0(1.0)$ & $27.4(1.0)$ \\
\hline & 1989 & $20.9(0.8)$ & $23.2(0.8)$ & $21.9(0.8)$ & $23.8(0.9)$ & $23.8(0.8)$ & $20.1(0.9)$ & $22.9(0.8)$ \\
\hline & 1992 & $11.2(0.4)$ & $13.1(0.5)$ & $14.8(0.5)$ & $11.4(0.4)$ & $13.5(0.5)$ & $10.4(0.5)$ & $12.6(0.5)$ \\
\hline & 1994 & $14.9(0.5)$ & $18.0(0.7)$ & $20.3(0.7)$ & $15.2(0.6)$ & $18.4(0.6)$ & $14.1(0.6)$ & $17.0(0.6)$ \\
\hline & 1996 & $13.1(0.5)$ & $12.7(0.5)$ & $17.4(0.6)$ & $11.1(0.4)$ & $14.7(0.5)$ & $11.0(0.5)$ & $13.2(0.5)$ \\
\hline & 1998 & $12.8(0.5)$ & $11.3(0.4)$ & $16.1(0.6)$ & $10.6(0.4)$ & $13.6(0.5)$ & $10.2(0.5)$ & $12.3(0.4)$ \\
\hline \multirow[t]{6}{*}{ Fats and oils } & 1984 & $2.3(1.0)$ & $2.3(1.0)$ & $1.7(1.0)$ & $1.8(1.0)$ & $2.2(1.0)$ & $2.0(1.0)$ & $2.1(1.0)$ \\
\hline & 1989 & $2.2(1.0)$ & $2.1(0.9)$ & $2.1(1.2)$ & $2.0(1.1)$ & $2.1(1.0)$ & $2.0(1.0)$ & $2.1(1.0)$ \\
\hline & 1992 & $1.8(0.8)$ & $1.6(0.7)$ & $1.9(1.1)$ & $1.2(0.7)$ & $1.6(0.7)$ & $1.3(0.7)$ & $1.5(0.7)$ \\
\hline & 1994 & $2.3(1.0)$ & $2.3(1.0)$ & $2.9(1.7)$ & $1.8(1.0)$ & $2.5(1.1)$ & $1.8(0.9)$ & $2.2(1.0)$ \\
\hline & 1996 & $2.5(1.1)$ & $1.5(0.7)$ & $2.1(1.2)$ & $1.3(0.7)$ & $1.9(0.9)$ & $1.4(0.7)$ & $1.7(0.8)$ \\
\hline & 1998 & $1.9(0.8)$ & $1.3(0.6)$ & $1.7(1.0)$ & $1.3(0.7)$ & $1.6(0.7)$ & $1.3(0.7)$ & $1.5(0.7)$ \\
\hline \multirow{6}{*}{ Sugars and refined carbohydrates $\ddagger$} & 1984 & $11.4(1.0)$ & $9.1(1.0)$ & $11.4(1.0)$ & $8.2(1.0)$ & $11.5(1.0)$ & $6.5(1.0)$ & $9.6(1.0)$ \\
\hline & 1989 & $12.2(1.1)$ & $10.5(1.2)$ & $12.6(1.1)$ & $9.1(1.1)$ & $12.1(1.1)$ & $8.1(1.2)$ & $10.6(1.1)$ \\
\hline & 1992 & $9.6(0.8)$ & $7.9(0.9)$ & $10.3(0.9)$ & $6.0(0.7)$ & $9.1(0.8)$ & $5.7(0.9)$ & $7.8(0.8)$ \\
\hline & 1994 & $12.8(1.1)$ & $11.1(1.2)$ & $14.6(1.3)$ & $8.4(1.0)$ & $13.2(1.1)$ & 7.5 (1.2) & $10.8(1.1)$ \\
\hline & 1996 & $14.0(1.2)$ & $10.3(1.1)$ & $15.4(1.4)$ & $8.6(1.0)$ & 13.7 (1.2) & 7.7 (1.2) & $11.3(1.2)$ \\
\hline & 1998 & $13.6(1.2)$ & $9.6(1.1)$ & $12.9(1.1)$ & $7.6(0.9)$ & $12.3(1.1)$ & $7.0(1.1)$ & $10.2(1.1)$ \\
\hline \multirow[t]{6}{*}{ Tortilla† } & 1984 & $11.7(1.0)$ & $16.8(1.0)$ & $8.7(1.0)$ & $18.5(1.0)$ & $13.1(1.0)$ & $17.0(1.0)$ & $14.1(1.0)$ \\
\hline & 1989 & $10.0(0.9)$ & $11.4(0.7)$ & $4.9(0.6)$ & $19.5(1.1)$ & $9.5(0.7)$ & $16.7(1.0)$ & $11.2(0.8)$ \\
\hline & 1992 & $5.4(0.5)$ & $7.8(0.5)$ & $4.7(0.5)$ & $8.7(0.5)$ & $6.2(0.5)$ & $8.8(0.5)$ & $7.1(0.5)$ \\
\hline & 1994 & $7.6(0.6)$ & $10.7(0.6)$ & $5.8(0.7)$ & $12.5(0.7)$ & $8.7(0.7)$ & $11.9(0.7)$ & $9.5(0.7)$ \\
\hline & 1996 & $8.6(0.7)$ & $9.8(0.6)$ & $7.6(0.9)$ & $10.0(0.5)$ & $8.4(0.6)$ & $10.8(0.6)$ & $9.2(0.7)$ \\
\hline & 1998 & $7.5(0.6)$ & $7.4(0.4)$ & $7.6(0.9)$ & $8.4(0.5)$ & $7.4(0.6)$ & $8.4(0.5)$ & $7.7(0.5)$ \\
\hline \multirow{6}{*}{ Sodał } & 1984 & $5.5(1.0)$ & $4.1(1.0)$ & $2.7(1.0)$ & $4.1(1.0)$ & $4.5(1.0)$ & $3.8(1.0)$ & $4.3(1.0)$ \\
\hline & 1989 & $7.7(1.4)$ & $5.1(1.2)$ & $4.5(1.7)$ & $4.4(1.1)$ & $5.7(1.3)$ & $4.6(1.2)$ & 5.5 (1.3) \\
\hline & 1992 & $5.4(1.0)$ & $3.4(0.8)$ & $4.6(1.7)$ & $4.0(1.0)$ & $4.2(0.9)$ & $4.0(1.1)$ & $4.2(1.0)$ \\
\hline & 1994 & $7.4(1.3)$ & $5.7(1.4)$ & $6.9(2.6)$ & $5.2(1.3)$ & $6.7(1.5)$ & $4.9(1.3)$ & $6.2(1.4)$ \\
\hline & 1996 & $7.7(1.4)$ & $4.5(1.1)$ & $6.3(2.3)$ & $4.2(1.0)$ & $6.1(1.4)$ & $4.3(1.1)$ & $5.4(1.3)$ \\
\hline & 1998 & 6.9 (1.3) & $5.2(1.3)$ & $6.8(2.5)$ & $5.0(1.2)$ & $6.1(1.4)$ & $5.2(1.4)$ & $5.9(1.4)$ \\
\hline
\end{tabular}

* Data obtained from the National Income and Expenditure Surveys 1984-1998; income and expenditure are expressed in US\$, estimated with the average exchange rate of each year's surveys. Income represents the sum of monetary and non-monetary three-month normalised reported income.

tCereals include tortillas.

$\ddagger$ Sugars and refined carbohydrates include soda. 
important factor that has not been considered in our analysis. We suspect that physical activity has declined over time in recent years, as a result of urbanisation, increased availability of motorised transportation and more sedentary occupations. Unfortunately, we do not have information at this time to confirm our suspicions. Neither have other risk factors, such as smoking, been considered to explain the causes of death studied.

Finally, mortality from these diseases can be reduced through adequate medical attention. Therefore, part of the differences in mortality rates among regions in Mexico may be due to differences in coverage and quality of medical attention, which has not been considered in this analysis.

\section{Conclusions}

SMRs due to diabetes, hypertension and AMI have increased dramatically in parallel with an increase in obesity. The association of overweight and obesity with mortality rates among regions at baseline, as well as their parallel evolution over time, suggests that overweight and obesity are playing an important role in the increasing trends observed in these three NCCDs. Overweight and obesity should, therefore, be considered public health problems and actions should be taken for their prevention and control. We were unable to consistently relate the changes in overweight, obesity or mortality from NCCDs with the total energy intake or food quantities purchased by adult equivalent. An increase in fat intake is evident from the dietary intake data, suggesting that increases in fat intake may explain the rise in overweight and obesity as well as mortality. However, the results are not supported by the changes in quantities of food purchased, probably due to methodological problems; therefore, the evidence is not conclusive. An increase in the purchase of sugars and refined carbohydrates, particularly soda, is worrisome and may be related to the increases in mortality due to NCCDs. Other factors such as changes in physical activity, which are not considered in the analysis, may explain the increment in the prevalence of overweight and obesity. Reliable information about food consumption and physical activity is required in order to assess their specific roles in the aetiology of obesity.

\section{Acknowledgements}

We would like to acknowledge Eric Monterrubio for his help in the configuration of the income-expenditure databases, Luis Vázquez Segovia for his assistance in the analysis and interpretation of the food expenditure databases, Drs. Steffano Bertotzi and Paul Gertler for their advice in the adjustment and interpretation of food expenditure data.

\section{References}

1 Chávez A, De Chávez M, Roldán A, Bermejo S, Avila A, Madrigal H. The Food and Nutrition Situation in Mexico: A Food Consumption, Nutritional Status and Applied Programs Tendencies Report from 1960 to 1990, 1st ed. Mexico City: Editorial Pax, Mexico, 1996.

2 Hernandez-Diaz S, Peterson K, Dixit S, Hernandez-Prado B, Parra S, Barquera S, Sepúlveda J, Rivera J. Association of maternal short stature with stunting in Mexican children common genes vs common environment. Eur. J. Clin. Nutr. 1999; 53: 938-45.

3 Frenk J, Frejka T, Bobadilla JL, Stern C, Lozano M, Sepúlveda $\mathrm{J}$, et al. The epidemiologic transition in Latin America [in Spanish]. Boletin de la Oficina Sanitaria Panamericana 1991; 111(6): 485-96.

4 Omran AR. The epidemiologic transition. A theory of the epidemiology of population change. Milbank Mem. Fund Quart. 1971; 49(4): 509-38.

5 Omran AR. The epidemiologic transition theory. A preliminary update. J. Trop. Pediatr. 1983; 29: 305-16.

6 Bobadilla J, Frenk J, Lozano R, Frejka T, Stern C. The epidemiologic transition and health priorities. In: Jamison D, ed. Disease Control Priorities in Developing Countries. New York: Oxford University Press, 1993.

7 Drewnowski A, Popkin BM. The nutrition transition: new trends in the global diet. Nutr. Rev. 1997; 55(2): 31-43.

8 Peña M, Bacallao J. Obesity and poverty: an emerging problem in the Americas. In: Peña MaBJ, ed. Obesity and Poverty: A New Public Health Challenge. PAHO Scientific Publication No. 576. Washington, DC: Pan American Health Organization, 2000; 132.

9 Barker DJ. The intrauterine environment and adult cardiovascular disease. Ciba Foundation Symp. 1991; 156 $3-10$.

10 Barker DJ. Fetal growth and adult disease. Br. J. Obstet. Gynaecol. 1992; 99(4): 275-6.

11 Barker DJ, Hales CN, Fall CH, Osmond C, Phipps K, Clark PM. Type 2 (non-insulin-dependent) diabetes mellitus, hypertension and hyperlipidaemia (syndrome $\mathrm{X}$ ): relation to reduced fetal growth. Diabetologia 1993; 36(1): 62-7.

12 Barker DJ, Martyn CN, Osmond C, Hales CN, Fall CH. Growth in utero and serum cholesterol concentrations in adult life. BMJ 1993; 307(6918): 1524-7.

13 Phillips DI, Hirst S, Clark PM, Hales CN, Osmond C. Fetal growth and insulin secretion in adult life. Diabetologia 1994; 37(6): 592-6

14 Anon. Urbanization and public health. WHO Chronicle 1967; 21(10): 428-35.

15 Popkin BM. The nutrition transition in low-income countries: an emerging crisis. Nutr. Rev. 1994; 52(9): 285-98.

16 Pan American Health Organization (PAHO)/World Health Organization (WHO). International Classification of Diseases, Revision 9 (ICD-9). Washington, DC: PAHO/WHO, 1978.

17 World Health Organization (WHO). International Statistical Classification of Diseases and Related Health Problems, ICD10. Geneva: WHO, 1992.

18 World Health Organization (WHO). World Health Statistics Annual. Geneva: WHO, 1999.

19 Sepúlveda-Amor J, Lezana MA, Tapia-Conyer R, Valdespino JL, Madrigal H, Kumate J. Nutritional status of pre-school children and women in Mexico: results of a probabilistic national survey [in Spanish]. Gaceta Medica de Mexico 1990; 126(3): 207-24.

20 Secretaría de Salud, Dirección de Epidemiología. Encuesta Nacional de Enfermedades Crónicas. Mexico DF: Secretaría de Salud, Dirección de Epidemiología, 1993.

21 World Health Organization (WHO). Obesity. Preventing and 
Managing the Global Epidemic. Report of a WHO Consultation on Obesity, June. Geneva: WHO, 1997.

22 National Center for Health Statistics (NCHS)/Centers for Disease Control (CDC). NCHS Growth Curves for Children, birth-18y. Series 11, 165. DHEW Publication (PHS) 781650. Washington, DC: US Government Printing Office, 1978.

23 Food and Nutrition Board Commission of Life Sciences, National Research Council. Recommended Dietary Allowances, 10th ed. Washington, DC: Subcommittee on the 10th edition of the RDAs, 1989.

24 SPSS, Inc. SPSS for Windows, Release 10.0.O. Chicago, IL: SPSS Inc., 1999.

25 Rivera J, Long K, Gónzalez-Cossío T, Parra S, Rivera M, Rosado J. Nutrición y Salud: Un Menú para la Familia. Cuadernos de Salud. Problemas Pretransicionales. Mexico: Secretaría de Salud, 1994.

26 Instituto Nacional de Salud Pública (INSP). Encuesta Nacional de Nutrición 1999. Tomo I. Niños Menores de 5 años. Cuernavaca Morelos: INSP, 2000.

27 Rivera-Dommarco J, Shamah T, Villalpando-Hernández S,
González de Cossío T, Hernández-Prado B, Sepúlveda J Encuesta Nacional de Nutrición 1999. Estado Nutricio en Niños y Mujeres en México. Cuernavaca Morelos: Instituo Nacional de Salvd Pública, 2001.

28 Flores M, Melgar H, Cortes C, Rivera M, Rivera J, Sepulveda J. Consumo de energía y nutrimentos en mujeres mexicanas en edad reproductiva. Salud Pública de México 1998; 40: $161-71$

29 Cuadernos de Salud. La Mortalidad en México: Registro, Estructura y Tendencias, 1st ed. Mexico: Secretaría de Salud, 1994.

30 Secretaría de Salud. Mortalidad 1998. Contexto Actual y Aspectos Relevantes. Perfiles Estadísticos No. 13. Mexico: Dirección General de Estadística e Informática, 1999.

31 Campirano F, Barquera S, Rivera J, Hernández-Prado B, Flóres-López ML, Monterrubio E. Estimation of energy under-reporting in obese and non-obese Mexican women using different equations: analysis of the Mexican National Nutrition Survey. Ann. Nutr. Metab 2001; 45(Suppl. 1): 146. 